\title{
FIB-SEM Sectioning Study of Decarburization Products in the Microstructure of HVOF-Sprayed WC-Co Coatings
}

\author{
Vasileios Katranidis $^{1} \cdot$ Sai Gu ${ }^{1} \cdot$ David C. Cox ${ }^{2} \cdot$ Mark J. Whiting ${ }^{3}$. \\ Spyros Kamnis ${ }^{4}$
}

Submitted: 23 January 2018/in revised form: 11 April 2018/Published online: 1 May 2018

(C) The Author(s) 2018

\begin{abstract}
The thermal dissolution and decarburization of WC-based powders that occur in various spray processes are a widely studied phenomenon, and mechanisms that describe its development have been proposed. However, the exact formation mechanism of decarburization products such as metallic $\mathrm{W}$ is not yet established. A WC-17Co coating is sprayed intentionally at an exceedingly long spray distance to exaggerate the decarburization effects. Progressive xenon plasma ion milling of the examined surface has revealed microstructural features that would have been smeared away by conventional polishing. Serial sectioning provided insights on the three-dimensional structure of the decarburization products. Metallic W has been found to form a shell around small splats that did not deform significantly upon impact, suggesting that its crystallization occurs during the in-flight stage of the particles. $\mathrm{W}_{2} \mathrm{C}$ crystals are more prominent on $\mathrm{WC}$ faces that are in close proximity with splat boundaries indicating an accelerated decarburization in such sites. Porosity can be clearly categorized in imperfect intersplat contact and oxidation-generated gases via its shape.
\end{abstract}

Vasileios Katranidis

v.katranidis@surrey.ac.uk

1 Department of Chemical and Process Engineering, University of Surrey, Guildford GU2 7XH, UK

2 Advanced Technology Institute, University of Surrey, Guildford GU2 7XH, UK

3 Department of Mechanical Engineering Sciences, University of Surrey, Guildford GU2 7XH, UK

4 Monitor Coatings, 2 Elm Road, Tyne and Wear NE29 8SE, UK
Keywords decarburization $<$ properties focused ion beam $<$ testing $\cdot$ HVOF $<$ processing .

imaging $<$ processing $\cdot$ wear-resistant coatings $<$ applications $\cdot$ WC-Co $<$ feedstock

\section{Introduction}

Thermal spray coatings for wear/corrosion-resistant applications have seen increased adoption by industry over the past decades, proving themselves as effective alternatives to the toxic hard chrome plating (Ref 1). Such thermally sprayed coatings are typically based on tungsten or chromium carbides in a cobalt, or cobalt/nickel-based alloyed binder, commonly referred to as hardmetals (Ref 2). Highvelocity combustion thermal spray methods such as $\mathrm{HVOF}$ and HVAF are particularly effective for the deposition of hardmetals owing to the high velocity of the material jets and relatively low deposition temperatures. In the case of WC-Co coatings, low deposition temperatures are vital due to their sensitivity to thermal decomposition and decarburization. Meanwhile, high particle velocities are necessary to achieve the deformation of particles impinging on the target surface, forming the coating.

The thermal dissolution and decarburization of WC-Co have been shown to embrittle the coatings and lower the carbide volume fraction (Ref 3). Ultimately, the thermal dissolution and decarburization of the carbides result in brittle coatings that offer poor structural durability (Ref $2,4,5)$. The mechanism of thermal dissolution of $\mathrm{WC}$ in Co and, ultimately, decarburization of WC-Co has been examined by a number of authors (Ref 2, 4-10) and most of the pathways that are responsible have been adequately described. It has been established that the processes of thermal dissolution and oxidation of $\mathrm{C}$ are discrete and are 
both acting in synergy, when the Co binder is able to melt in-flight (Ref 4, 11). Coatings that have suffered WC thermal dissolution and decarburization typically demonstrate characteristic microstructural features that include the dissolution/decarburization products, as well as significant portions of amorphous phases in the binder. Affected WC grains are typically surrounded by the epitaxially grown semicarbide $\left(\mathrm{W}_{2} \mathrm{C}\right)$. Other dissolution-decarburization products are metallic tungsten $(\operatorname{Ref} 4,6,7)$ and solid solution $\eta$-phases $\mathrm{M}_{6} \mathrm{C}$ (e.g., $\mathrm{Co}_{3} \mathrm{~W}_{3} \mathrm{C}$ ) or $\mathrm{M}_{12} \mathrm{C}$ $\left(\mathrm{Co}_{6} \mathrm{~W}_{6} \mathrm{C}\right)($ Ref 2,5$)$, which are dispersed in the binder. Such $\eta$-phases can be formed during post-spray annealing (or equivalent secondary cooling conditions) (Ref 12-14) and are brittle, compromising the coating's wear resistance (Ref 5). So far, the morphology of the observed metallic W polycrystalline precipitates has been arbitrary, not presenting a clear morphological pattern. The exact occurrence of the conditions for $\mathrm{W}$ crystallization is not established yet. Stewart et al. (Ref 7), working on HVOF, and Zhan et al. (Ref 6), working on atmospheric plasmasprayed WC-Co, suggest that nucleation of $\mathrm{W}$ initiates during the solidification of particles post-impact, while Verdon et al. (Ref 4), working on HVOF, support that it occurs during the flight of particles, enabled by the volatile temperature profile experienced by the particles in-flight (Ref 15).

This work aims to contribute to the understanding of the circumstances of metallic $\mathrm{W}$ nucleation by presenting a closer examination on the three-dimensional morphological features of the WC decarburization products, focusing especially on the structure of metallic W. Previous work (Ref 3) has demonstrated metallic W forming continuous rims, which extended along the splat boundary of fine splats. Further analysis of these structures takes place in this study.

\section{Experimental Procedure}

A commercial agglomerate sintered powder of WC-17Co mass\% with intercepts $\mathrm{D} 10$ at $9-13 \mu \mathrm{m}$ and D90 at $25-33 \mu \mathrm{m}$ and median particle size of $18.9 \mu \mathrm{m}$ (H.C. Starck, AMPERIT 526) (Ref 16) was employed to coat the substrates. Prior to deposition, the steel surface of the substrate was activated via grit blasting with alumina particles of $46 \mu \mathrm{m}$ median size at a distance of $100 \mathrm{~mm}$. Subsequently, high-pressure air blasting was used to remove any remaining grit on the substrate surface. Monitor Coating's (UK) HVOF torch, which has been designed and built in-house, was used for the coating deposition. The patented technology (Ref 17) comprises of an isentropic plug nozzle to accelerate the exhaust gases to supersonic velocities reaching Mach 2.7. The process parameters for the gun were previously optimized in-house using Oseir's SprayWatch system. Following the deposition process, the coating was cut and polished following standard metallographic techniques. The phase composition of the powder and coatings was examined by $\mathrm{x}$-ray diffraction (XRD) (PANalytical X'Pert Pro, $45 \mathrm{kV}, 40 \mathrm{~mA}$ ) utilizing $\mathrm{Cu} \mathrm{K} \alpha$ $(\lambda=0.15406 \mathrm{~nm})$ radiation and incidence angle of $1^{\circ}$. The diffraction data were collected over a range of $2 \theta\left(30^{\circ}-\right.$ $50^{\circ}$ ), the step size was $0.01^{\circ}$, and the time per step was $2 \mathrm{~s}$. Cross sections of the coating were obtained with the SEM (JEOL, JSM-7100F) equipped with backscatter electron detector (BSE) and EDS analysis. EDS analysis (point and area) was employed to quantify and spatially discriminate against the decarburization products, Co-rich binder and WC in the microstructure. For the EDS measurements, the acceleration voltage of the electron beam was set at $5 \mathrm{kV}$, making sure that it still was capable of exciting core electron from tungsten (characteristic x-ray of tungsten M shell is $1.774 \mathrm{eV}$ ). This was done in order to minimize the interaction volume of the incident electron beam and correspondingly increase the accuracy of the point measurements. A TESCAN FERA3 fully integrated Xe + plasma FIB-SEM was used for the sectioning studies. The produced image stacks were processed with the open-source image analysis java software Image $\mathbf{J}$ developed in National Institutes of Health (USA) (Ref 18). In order to probe the three-dimensional features of the microstructure and decarburization products, the plasma FIB-SEM was employed to perform three operations. First, a layer of platinum was deposited via sputtering on a square area of approximately $13 \mu \mathrm{m}^{2}$, on a site on the cross section of the examined coating (Fig. 1a). Subsequently, material was removed via ion milling, selectively around the platinumdeposited square layer, as shown in Fig. 1(a). In a later step, progressive ion milling was used to remove consecutive layers of coating of dimensions of $10 \times 13 \times 0.05 \mu \mathrm{m}^{3}$. At each iteration of the milling process, a high-definition SE image of the exposed face of the coating was captured. Figure 1(b) presents the site after the completion of the ion milling and image capture. The initial step of platinum deposition was necessary to shield the underlying coating from the high-energy $\mathrm{Xe}+$ ions that were used for the ion milling, making sure that the removed layers are consistent and precise in dimensions. Table 1 (Ref 19) presents the mean particle velocity and temperature at the optimum spray distance of $120 \mathrm{~mm}$ and the distance used for this study $(240 \mathrm{~mm})$. 

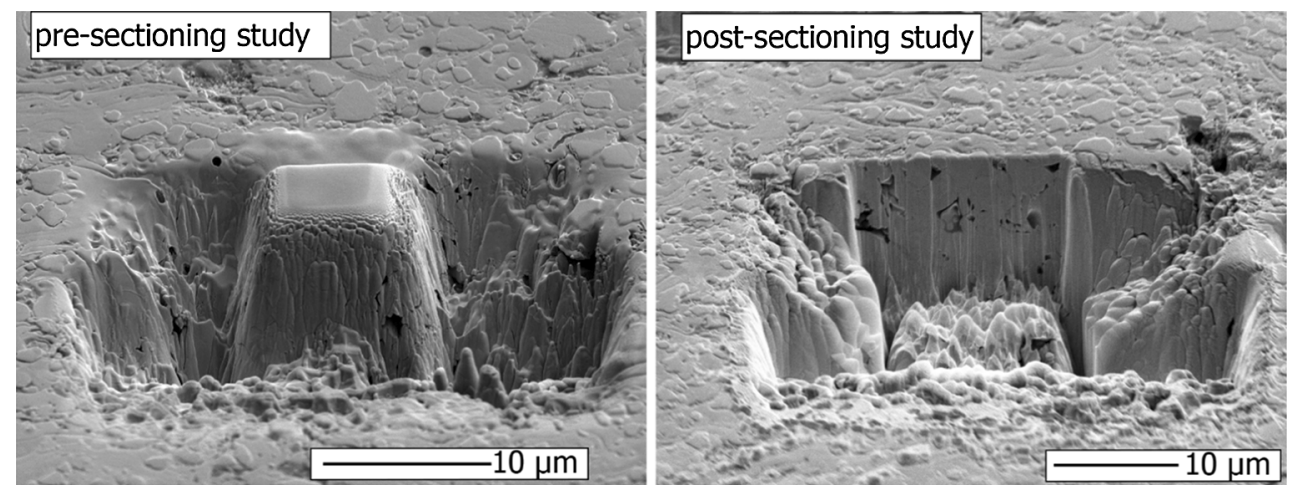

Fig. 1 Left: site before the FIB-SEM sectioning study, right: site after the sectioning study

Table 1 Average particle velocity and temperature measurements at 120 and $240 \mathrm{~mm}$ distance from gun nozzle (Ref 19)

Spray distance, $\mathrm{mm}$ Particle velocity, $\mathrm{m} / \mathrm{s}$ Particle temperature, $\mathrm{K}$

\begin{tabular}{lll}
\hline 120 & 860 & 1500 \\
240 & 630 & 1800 \\
\hline
\end{tabular}

\section{Results and Discussion}

\section{Microstructure and Phase Composition}

Previous work on the effects of the spray kinematic parameters on various coating properties (Ref 3, 19) demonstrated that the increased spray distance resulted in coatings with significant decarburization of WC, which was attributed to the respective longer dwell time of the particles in-flight. Moreover, oblique spray angles proved to promote the preferential rebounding of particles that did not meet the critical impact parameters (temperature and normal component of velocity). Thus, there is a biased deposition of hotter particles, versus colder, under oblique spray angles due to their associated increased plasticity. This means that, irrespective of spray distance, oblique spray angles are positively correlated with increased quantities of decarburization products in the microstructure, since they stem from higher-temperature particle impingements. The process setup used in this work is optimized so that the highest particle velocity and lowest temperature occur at $120 \mathrm{~mm}$ of spray distance (Ref 19) (Table 1). However, the microstructural observations that are made in this work are made on a coating sprayed at $240 \mathrm{~mm}$ and at $30^{\circ}$ of spray angle, which presented the richest microstructure in terms of WC decarburization products, for the reasons discussed above. It can be seen that the mean particle temperature at $240 \mathrm{~mm}$ (Table 1) is slightly higher than the melting temperature of cobalt [1770 K (Ref 20)]. Hence, the majority of the particles are expected to impinge with the binder at a liquid state. The mean particle velocity is also reduced at $240 \mathrm{~mm}$, indicating a drop in the HVOF jet velocity field at distances longer than $120 \mathrm{~mm}$.

The XRD patterns of the examined coating are presented in Fig. 2. Clear peaks that are related to $\mathrm{W}_{2} \mathrm{C}$ and metallic $\mathrm{W}$, along with a plateau in the $2 \theta$ range of $40^{\circ}-47^{\circ}$, are identified in the diffraction. The observed plateau in the intensity pattern $\left[2 \theta=\left(40^{\circ}-47^{\circ}\right)\right]$ is associated with the amorphous phase in which the Co-rich binder (saturated with $\mathrm{W}$ and $\mathrm{C}$ ) is captured owing to the quenching during splat formation (Ref 4, 6, 7).

In Fig. 3, a typical example of the microstructure of the coating is presented, and Fig. 3(a) shows a secondary electron image (SE) and Fig. 3(b) a backscatter electron (BSE). As heavier elements, such as tungsten, appear brighter in the BSE images, the different grades of gray that are seen on the binder phase in Fig. 3(b) can be attributed to varying degrees of dissolution of $\mathrm{W}$ (which is evidence of the melting of the binder in-flight (Ref 2,4).

In this way, individual neighboring splats, which have sustained different degrees of WC thermal dissolution, can be identified. Beyond, any differences in the grayscale of

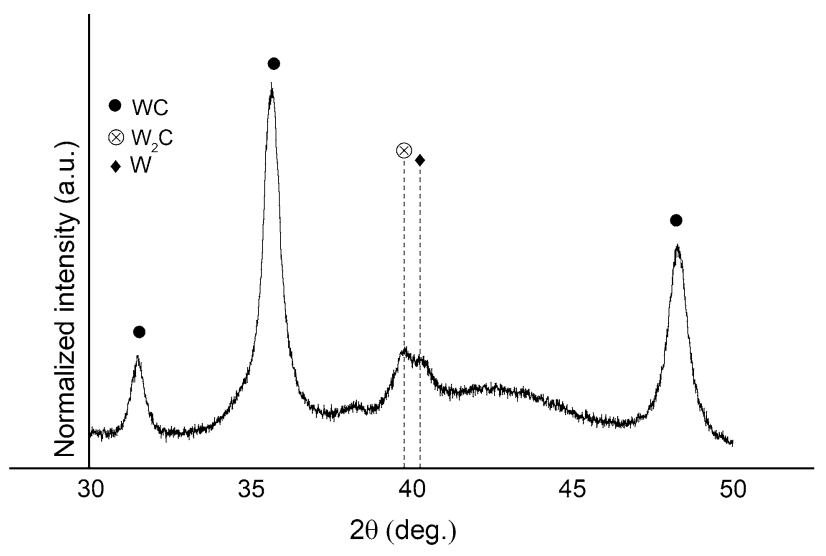

Fig. 2 XRD diffractogram of the examined coating sprayed at $240 \mathrm{~mm}$ and at $30^{\circ}$ of spray angle 

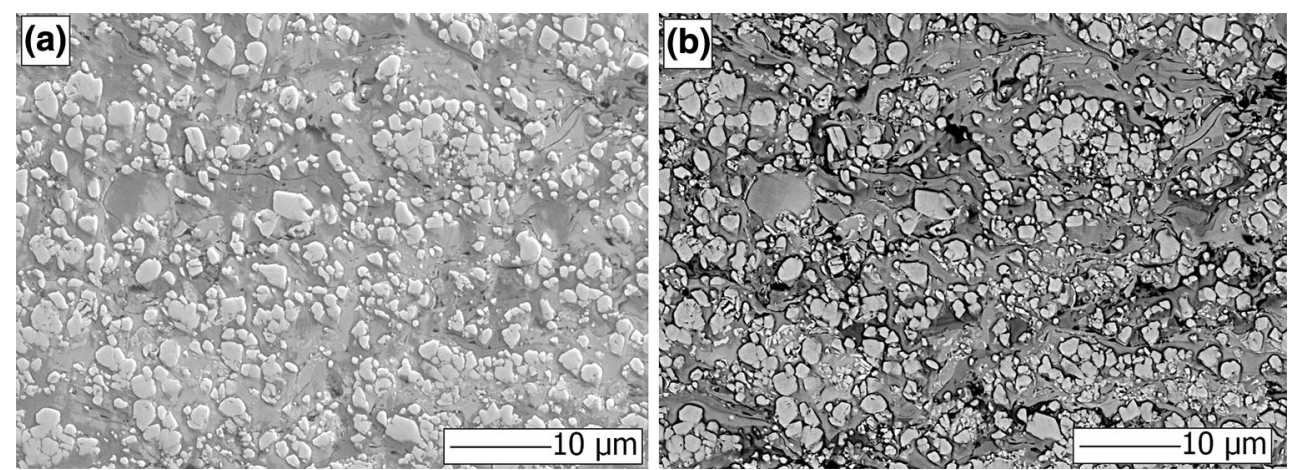

Fig. 3 Microstructure from the examined coating sprayed at $240 \mathrm{~mm}, 30^{\circ}$ and $2010 \mathrm{~mm} / \mathrm{s}$ (a) SE, (b) BSE

the binder phases, individual splats can also be discriminated by the visible splat boundaries in Fig. 3(a). The intensely curved and tortious nature of such splat boundaries is expected from particle impingements with a liquid binder phase. Lastly, some dispersed bright precipitates of arbitrary shape are shown in Fig. 3(b). These are metallic $\mathrm{W}$ grains, which are known products of the thermal dissolution and decarburization of WC (Ref 4).

As shown in Ref 3 , some very fine (up to $5 \mu \mathrm{m}$ in diameter) and intensely decarburized particles which were captured in the coating maintained their spherical shape and presented continuous rims of metallic $\mathrm{W}$, extending along their boundary. Such features are presented in Fig. 4, where two sites are captured by the secondary and BSE detector in the SEM. It is evident that the growth of $\mathrm{W}_{2} \mathrm{C}$ is possible only where there is thermal dissolution of the WC in the binder. In Fig. 4(c) and (d), the right side of the WC grain presents notable $\mathrm{W}_{2} \mathrm{C}$ crystals extending in the binder. Conversely, the left side of the WC grain is adjacent to neighboring splat boundary which suggests that it was exposed to the HVOF jet during the flight of that particle. The lack of any binder in contact with the left side of the WC grain in Fig. 4(c) and (d) did not result in any $\mathrm{W}_{2} \mathrm{C}$ formation, demonstrating the necessary role of the binder to the formation of the semicarbide, in agreement with $\mathrm{Li}$ et al. (Ref 21).
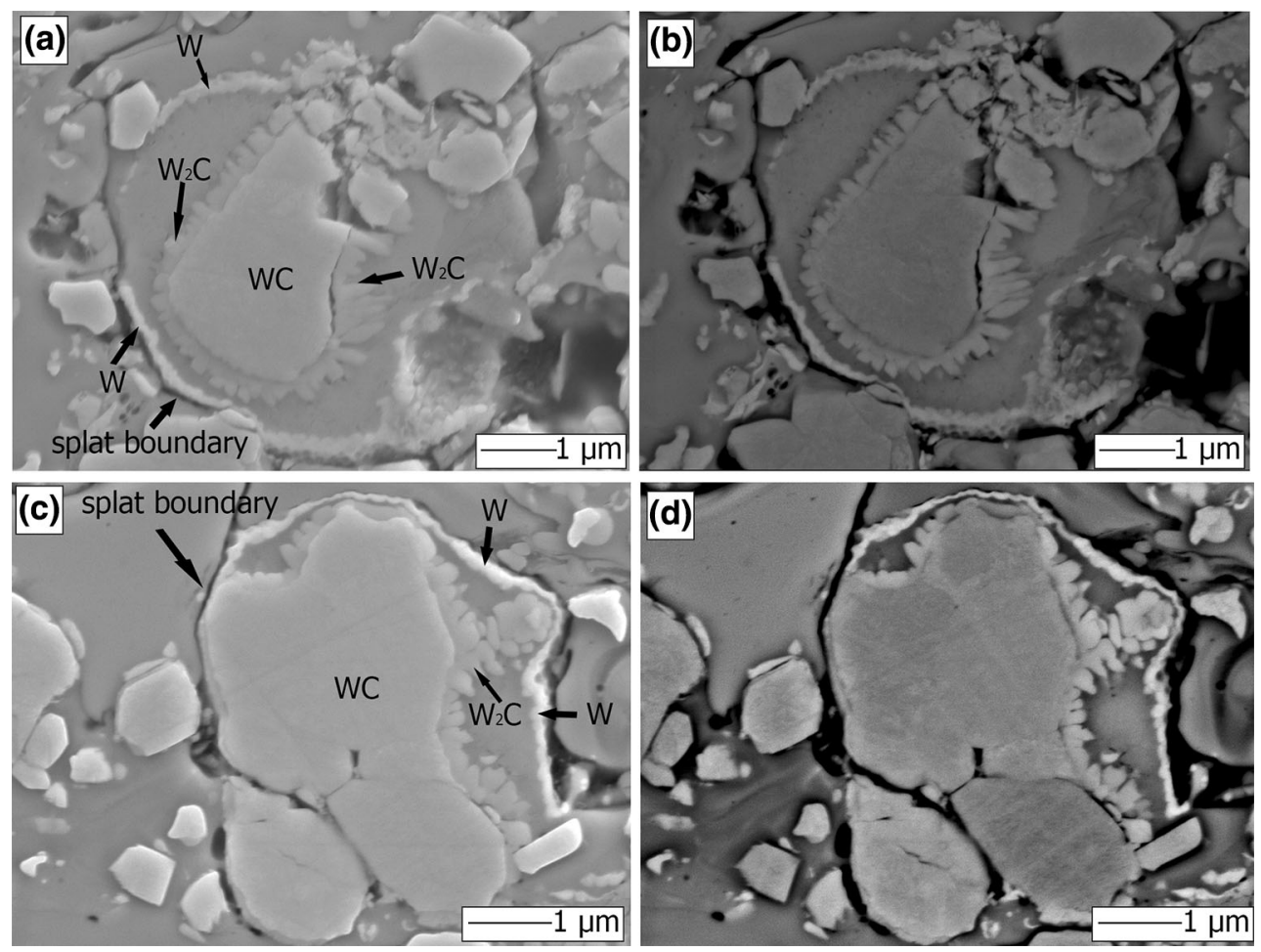

Fig. 4 Individual fine particles demonstrating a metallic W-rim that extends along the splat boundary (a) site 1 SE, (b) site 1 BSE, (c) site 2 SE, (d) site 2 BSE 
The continuous rim structures along the splat boundary are brighter than the WC grains in the BSE images (Fig. 4b, d) supporting the proposal that they are in fact metallic tungsten. In addition, EDS analysis in similar sites (point \#1 and \#2 in Fig. 5, Table 2) demonstrates that such rim structures are composed primarily by tungsten (77\%) and oxygen (11\%) with smaller fractions of Co and C (5\%), whereas the Co-rich binder consists principally of Co $(46 \%)$ and $\mathrm{W}(34 \%)$ with similar lower fractions of oxygen and carbon (point \#3 in Fig. 5, Table 2).

In Fig. 6, further EDS elemental mapping at the same site shown in Fig. 4(c) and d takes place. In Fig. 6 O map, the detected oxygen appears to follow the splat boundary and is mostly detected in the lower region of the image, where there is a wider gap between the adjacent splats. In addition, the oxygen counts are not so evident on the upper part of the image (Fig. 6, O map), where the thicker part of the examined rim structure exists. This indicates that the detected oxygen originates exclusively from the splat boundary itself which lies adjacent to the examined rim structure. The concentration of oxygen species on the splat boundaries has been also observed by Verdon et al. (Ref 4), where it is attributed to the reaction of the particle with oxygen in-flight.

The spatial distribution of Co (Fig. 6 Co map) corresponds to the regions where the Co-rich binder lies and it is clearly absent from the examined rim structure. Finally, the tungsten spatial distribution in Fig. $6 \mathrm{~W}$ matches the WC grains and the studied rim structure, confirming a significant presence of $\mathrm{W}$ in it. There is also a notable presence of $\mathrm{W}$ in the Co-rich binder that lies between the intensely decarburized WC grain and the rim structure in Fig. $6 \mathrm{~W}$ map. This is attributed to the diffusion of $\mathrm{W}$ species from the WC when the Co binder was at a liquid state. Considering the insights on the locality of the detected elements, provided by Fig. 6 , the $\mathrm{O}$, Co and $\mathrm{C}$ fractions that are measured on the examined rim structure in Fig. 5 (points \#1 and 2 in Table 2) can be attributed to adjacent

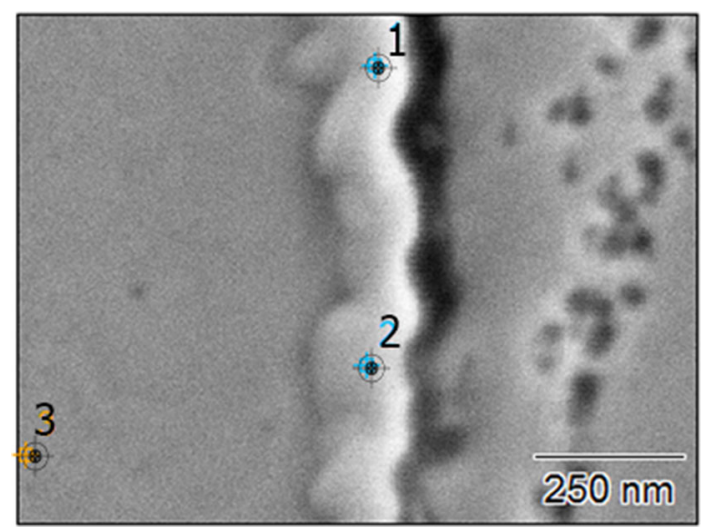

Fig. 5 EDS point measurements on a site featuring a metallic W-rim
Table 2 At.\% EDS measurements of the constituting elements

\begin{tabular}{|c|c|c|c|c|}
\hline & $\mathrm{C}$ & $\mathrm{O}$ & Co & W \\
\hline \multicolumn{5}{|c|}{ EDS point measurements on W-rims (at.\%) } \\
\hline Site \#2 pt1 & 6.1 & 11.3 & 5.4 & 77.2 \\
\hline Site \#2 pt2 & 5.3 & 11 & 6.1 & 77.5 \\
\hline Site $\# 2$ pt3 & 5.9 & 5.8 & 40.6 & 47.7 \\
\hline
\end{tabular}

phases that lie in the interaction volume of the EDS point measurement, and not on the rim structure itself. Thus, the examined rim structure can confidently be identified as tungsten.

The fact that the spats featured in Fig. 4 exhibit very low aspect ratio (i.e., maintained their circularity) suggests that they did not deform significantly upon impingement, indicating that they have undergone a solid-to-solid impingement. However, the existence of significant quantities of $\mathrm{W}_{2} \mathrm{C}$ and metallic $\mathrm{W}$ is evidence of high degree of thermal dissolution and decarburization. These two observations suggest that the particles were able to melt, react with oxygen in-flight, recrystallize and impinge in the solid state. The high specific surface area of such fine particles (Fig. 4) renders them sensitive to temperature volatility (Ref 22) and in-flight oxidation (Ref 23) that has been demonstrated to occur in the HVOF jet (Ref 15). The resolidification of particles lower than $10 \mu \mathrm{m}$ in-flight, prior impingement, is also discussed in Ref 7, based on modeling of the temperature history of particles of different sizes in an HVOF jet.

Furthermore, even if fine particles such as the ones shown in Fig. 4 did impinge at a two-phase state, the continuous W-rims could not have been formed post-particle impact since the undercooling caused by the splat quenching would not be uniform around the impinging particle, which would be needed for the homogenous crystallization of a W-rim with constant thickness (Fig. 4). On this basis, the most logical explanation for the features shown in Fig. 4 is that the fine particles impinged while solid having crystallized in-flight. Meanwhile, such small particles are prone to get carried away by the rebounding jets close to the substrate owing to their low momentum (Ref 24). Thus, the exceedingly long spray distance of $240 \mathrm{~mm}$ that is used in this study plays an additional role in promoting the deposition of small particles since the velocity of the HVOF jet is reduced with increasing spray distance (Table 1).

However, the specifications of the used powder do not explain the existence of such fine particles, like the ones shown in Fig. 4. In Fig. 7, details of the morphology of the powder particles can be seen. A significant degree of porosity is observed in the structure of the individual 
Fig. 6 EDS map of the site featured in Fig. 4(c) and (d)
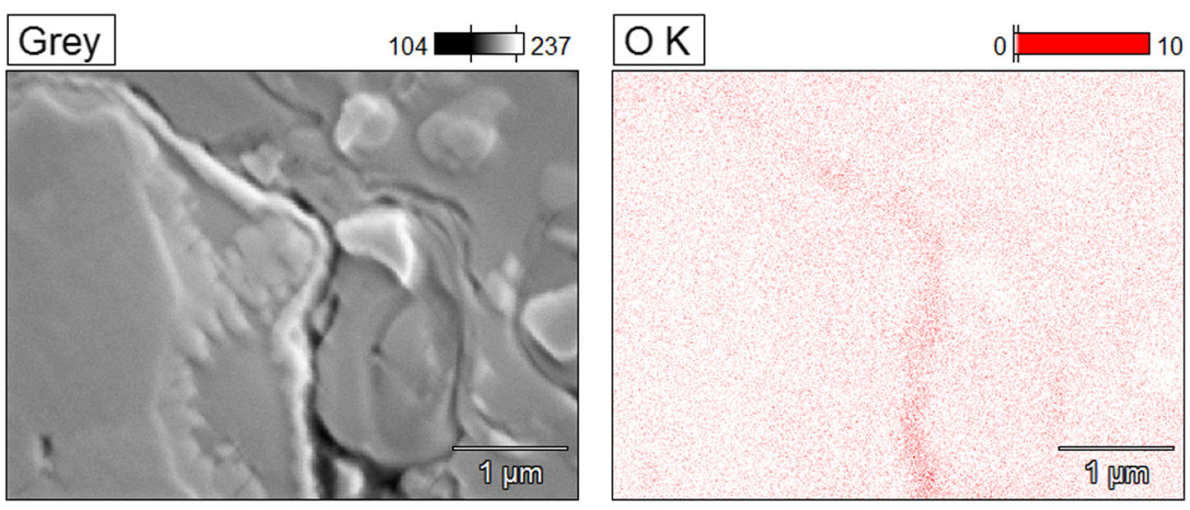

\section{CoL}
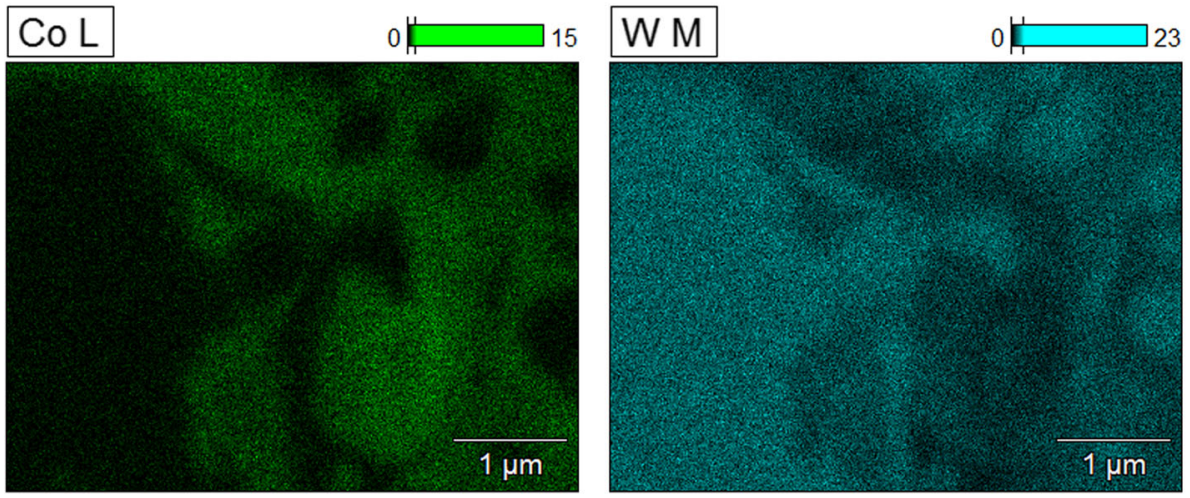
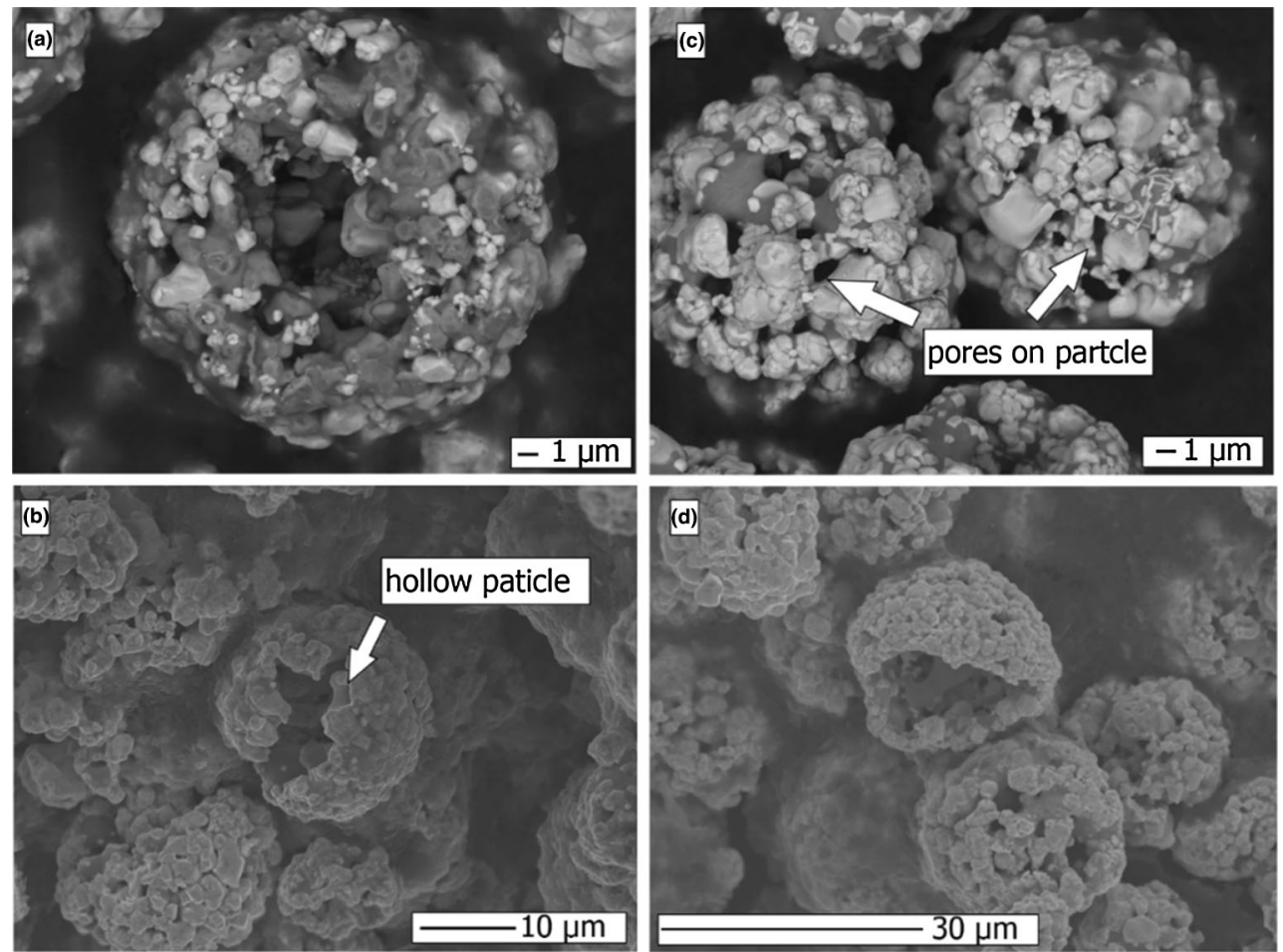

Fig. 7 SEM (a) BSE, (b) SE, (c) BSE, (d) SE images of individual powder particles offering detailed evaluation of their morphology

particles; moreover, in many cases the particles are hollow spheres which have lost a part of their shell, leaving them at a curved flake shape (Fig. 7a, b, and d). It is not inconceivable that such flawed particles break into smaller fractions, once Co is able to melt in-flight, which would 
explain the existence of very fine powder particles in the microstructure (Fig. 4).

Alternatively, the equivalent specific surface area of very fine particles could be achieved by larger particles with high degree of porosity, such as the periphery of the particles shown in Fig. 7. Kamnis et al. (Ref 22) have demonstrated that porous particles respond to drag forces more effectively and reach higher temperatures in-flight, owing to their high specific surface area.

\section{FIB Sectioning Study}

The resulting stack of 211 images contained the microstructural information of a volume of approximately $11 \mu \mathrm{m}^{3}$ of the coating. Lastly, due to the porosity in the coating, some curtaining (vertically aligned textural features) is evident in the FIB images below (Fig. 8, 9, 10, and 11). In Fig. 8, a montage of eight consecutive images of the same site with a step size of $50 \mathrm{~nm}$ in the third dimension is presented. A spherical pore is progressively revealed, located adjacent to an intersplat gap that is maintained unchanged along the third dimension. Such spherical pores in the Co-rich binder phase of WC-Co coatings have been previously observed in APS (Ref 25) and HVOF-sprayed (Ref 3,6) coatings and are attributed to the reaction of diffusing oxygen and carbon species forming $\mathrm{CO}$ or $\mathrm{CO}_{2}$ in the liquid binder. Naturally, in HVOF-sprayed coatings, such pores have diameters well below a micrometer, owing to the limited deposition temperature and short dwell time of the particles in-flight. Conversely, in the case of plasmasprayed coatings, gaseous $\mathrm{CO} / \mathrm{CO}_{2}$ pores can be many times larger (Ref 25) due to the significantly higher deposition temperatures which allow for higher degrees of thermal dissolution and decarburization. Figure 8 demonstrates that porosity in the coating can be categorized in spherical, gaseous pores that were formed in-flight and intersplat gaps that resulted from imperfect compaction post-particle impingement.

In Fig. 9, thirty consecutive images featuring a splat boundary with a metallic W-rim formation can be seen. The distance between the images in the third dimension is $50 \mathrm{~nm}$. The metallic W-rim can be clearly seen in all the iterations in Fig. 9 meaning that it is constant along the third dimension. Thus, it is more appropriate to speak of a metallic W-shell that covers the splat boundary, rather than a rim. In agreement with the W-shells shown in Fig. 4, the $\mathrm{W}$-shell in Fig. 9 is close to a highly dissolved WC grain with evident $\mathrm{W}_{2} \mathrm{C}$ crystallites grown toward it.

The discovery of metallic W-shells on the boundaries of fine particles which have remained undeformed in the microstructure provides proof of the in-flight formation of $\mathrm{W}_{2} \mathrm{C}$ and metallic $\mathrm{W}$. Considering the case of larger, twophase particles impingements, studies in plasma-sprayed

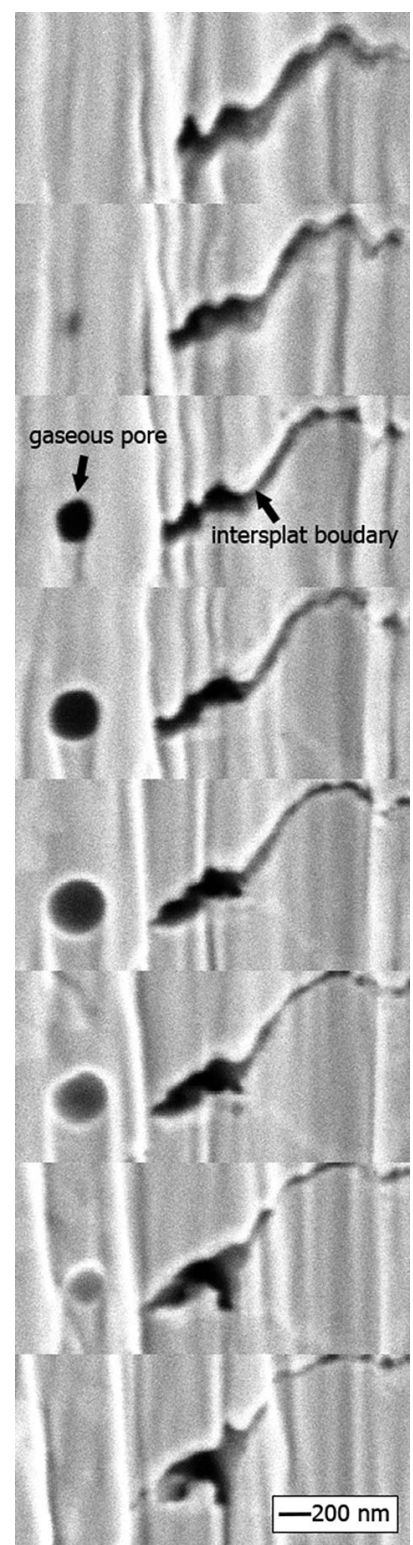

Fig. 8 Montage of eight images (step size $50 \mathrm{~nm}$ ) featuring a spherical gaseous pore and an intersplat gap

coatings have shown that the majority of $\mathrm{W}_{2} \mathrm{C}$ is formed inflight (Ref 5,6) along with small quantities of metallic W and $\eta$-phases. The formation of metallic $\mathrm{W}$ and $\eta$-phases was found to be dependent on the cooling rate of the captured particles (Ref $6,12,14)$. On these grounds, the formation of metallic $\mathrm{W}$, post-impingement, cannot be excluded for larger particles which impinge at a two-phase state, as advocated by Ref 7 . However, the existence of amorphous binder in the coating (Fig. 3) indicates significant undercooling upon particle impact, which contradicts the notion that metallic $\mathrm{W}$ had sufficient time to crystallize post-impact. The discussion above suggests that the crystallization conditions for metallic $\mathrm{W}$ can occur both in- 


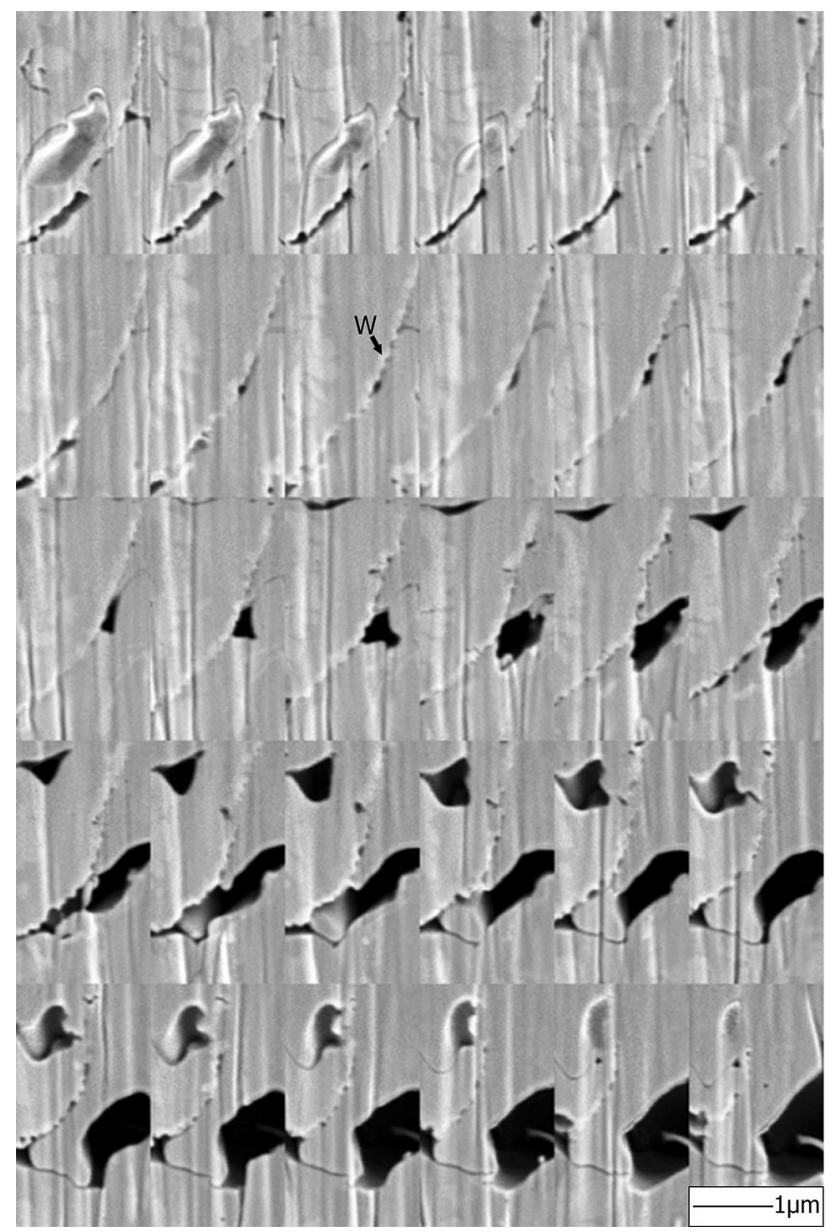

Fig. 9 Montage of thirty images (step size $50 \mathrm{~nm}$ ) featuring metallic W-shell along a splat boundary

flight and post-impingement and that they are a function of the particle size, morphology and spray method.

WC grains are prone to fast dissolution when in contact with liquid Co (Ref 4, 8). The diffusion of $\mathrm{C}$ is faster that $\mathrm{W}$, owing to its lower atomic mass (Ref 5, 6). Concurrently, a particle with liquid binder is exposed to significant oxygen presence due to air entrainment in the HVOF jet (Ref 26). Carbon that reaches the binder interface with the oxidizing jet can be readily removed by the formation of $\mathrm{CO}$ or $\mathrm{CO}_{2}$, which is the most favorable reaction for the W-Co-C-O system above $1000 \mathrm{~K}$ (Ref 7) (well below the temperatures experienced by particles in-flight, as shown in Table 1). Such oxidation of $\mathrm{C}$ can also occur in the liquid binder, from diffusing $\mathrm{C}$ and $\mathrm{O}$ species (Ref 25). The selective removal of $\mathrm{C}$ at the particle interface is the driving force for auxiliary thermal dissolution of the WC grains in proximity, which aims at re-establishing the $\mathrm{C}$ concentration balance. More importantly, it has been shown that the solubility of $\mathrm{W}$ in the binder is a function of both temperature (Ref 27) and carbon content, increasing with decreasing carbon content (Ref 28). Considering the kinetics of the dissolution-decarburization process as described above, the binder interface is predisposed to excessive accumulation of diffusing $\mathrm{W}$ species. In addition, the solubility of $\mathrm{W}$ close to the binder interface with the HVOF jet is expected to be increased owing to the local low concentration of $\mathrm{C}$ due to oxidation. Yet, the same region is subjected to the intense temperature variations experienced by the particles in-flight, enabling the crystallization of $\mathrm{W}$.

It is important to note that, as $\mathrm{Li}$ et al. (Ref 21) demonstrated experimentally, the thermal dissolution of $\mathrm{WC}$ is primarily responsible for the occurrence of $\mathrm{W}_{2} \mathrm{C}$ (not oxidation) and that oxidation on the interface of the liquid binder (removal of $\mathrm{C}$ and accumulation of $\mathrm{W}$ ) is necessary to yield metallic W. It is therefore reasonable to suggest that the high-aspect-ratio metallic $\mathrm{W}$ crystallites that have been observed in the relevant literature (Ref $4,5,29)$ can in fact be the fragments of the W-shells formed in-flight and mixed with the binder during the intense plastic deformation during the splat formation, upon the impingement of larger particles.

Figure 10 features an exposed splat boundary which is covered by a continuous shell, resembling the morphology that was previously characterized as metallic $\mathrm{W}$. The right part of Fig. 10 is a montage of 8 successive images of the splat boundary (highlighted on the left part of Fig. 10), expanding along the third dimension at a $50 \mathrm{~nm}$ step size. Unlike conventional polishing methods, the FIB milling removes material in highly tailored and precise manner which relies in dislocation of individual atoms. This enabled the survival of nanofeatures which would have been smeared away by any conventional polishing route. Such features are the nanostructures of globular shape which exist on the surface of the exposed splat (Fig. 10). These globules lie on what appears to be a shell structure covering the entire splat boundary, much like the metallic W-shells that have been observed other sites. Considering Fig. 4(a) and (b), the lower right part of the examined particle demonstrates that the $\mathrm{W}$-shell seems to be composed of globular structures of similar size as the ones featured in the exposed splat boundary in Fig. 10. This suggests that these globules could be metallic W crystals which nucleated on the particles periphery in-flight. Their small size can be attributed to the local availability of $\mathrm{W}$ species and the temperature history of the particle itself. The melting point of metallic tungsten is $3687 \mathrm{~K}$ (Ref 30), much higher than the temperature that particles experience in-flight. Although the metallic $\mathrm{W}$ melting point is expected to be decreased due to the interaction of $\mathrm{W}$ with Co and $\mathrm{C}$ species, it is not inconceivable that it will stay high enough so that once metallic tungsten crystallizes on the particle-gas interface in-flight, it will remain solid until particle impingement. Thus, discrete $\mathrm{W}$ nanocrystals can 


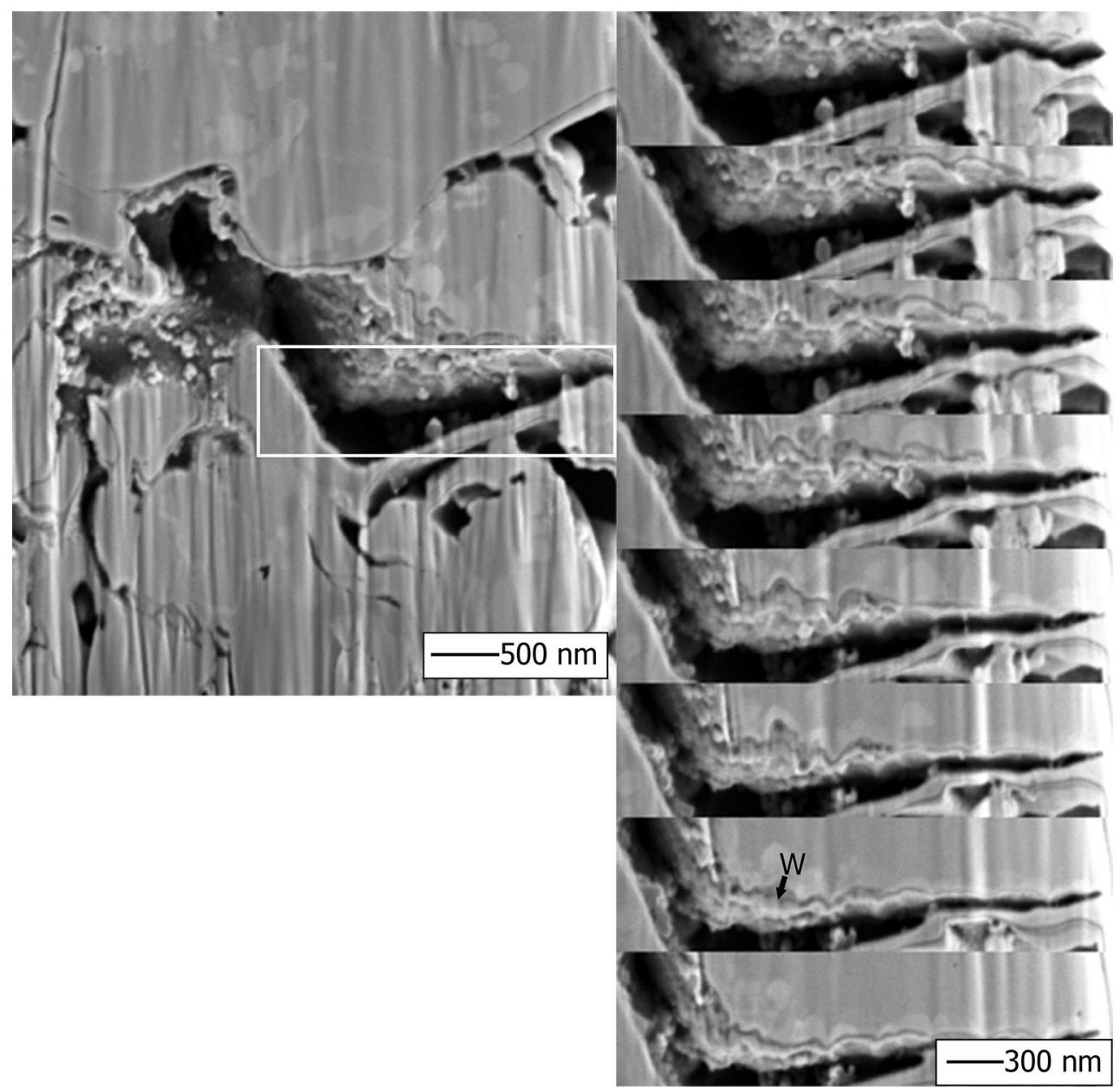

Fig. 10 Left: region of an exposed intersplat gap with what appears to be a W-shell, demonstrating nanoglobules, right: montage of eight images (step size $50 \mathrm{~nm}$ ) featuring the $\mathrm{W}$-shell

be the result of crystallization of tungsten at different stages during the flight of the particle.

In Fig. 11, the three-dimensional morphology of the single $\mathrm{WC}$ grain which is covered by $\mathrm{W}_{2} \mathrm{C}$ crystals is revealed. It can be seen that the $\mathrm{W}_{2} \mathrm{C}$ crystals extend outwards radially from the parent WC grain and can reach up to $350 \mathrm{~nm}$ in length. The $\mathrm{W}_{2} \mathrm{C}$ growth is epitaxial and has been reported to be either columnar (Ref 5-7) or uniform (Ref 4, 7).

The choice between uniform and columnar morphology of the semicarbide seems to be dependent on the size of the parent WC grain. Smaller WC grains appear to be surrounded by a uniform $\mathrm{W}_{2} \mathrm{C}$, while larger ones by epitaxially grown $\mathrm{W}_{2} \mathrm{C}$ crystallites. This behavior suggests that the size and growth kinetics of the $\mathrm{W}_{2} \mathrm{C}$ crystallites are independent of the size of the parent $\mathrm{WC}$ grain. As the $\mathrm{W}_{2} \mathrm{C}$ crystallites extend away from the parent $\mathrm{WC}$, they become thinner, which can be explained by the progressive drop in the concentration of $\mathrm{W}$ and $\mathrm{C}$, due to their diffusion in the liquid binder.

\section{Conclusions}

In this work, attention is given on the morphological features of known decarburization products of WC. The plasma FIB-SEM was used to ion-mill and capture images from a volume of the coating, aiming to extract insights on the three-dimensional structure of the $\mathrm{W}_{2} \mathrm{C}$, metallic $\mathrm{W}$ and porosity. The high degree of porosity and flaws in the starting powder has resulted in the spraying and capturing of fine particles $(<5 \mu \mathrm{m})$ which demonstrated insignificant plastic deformation upon impact and continuous rims of metallic $\mathrm{W}$ extending along the splat boundary. It has been shown that the $\mathrm{W}$-rims are in fact $\mathrm{W}$-shells that cover consistently sections of the splat boundary face. Such isomorphic structures indicate that metallic $\mathrm{W}$ is formed inflight, which also explains the insignificant plastic deformation owing to solid-to-solid particle impacts. It is suggested that the high-aspect-ratio $\mathrm{W}$ precipitates that have been reported in the literature are actually fragments of such metallic $\mathrm{W}$-shells that have been mixed with the 


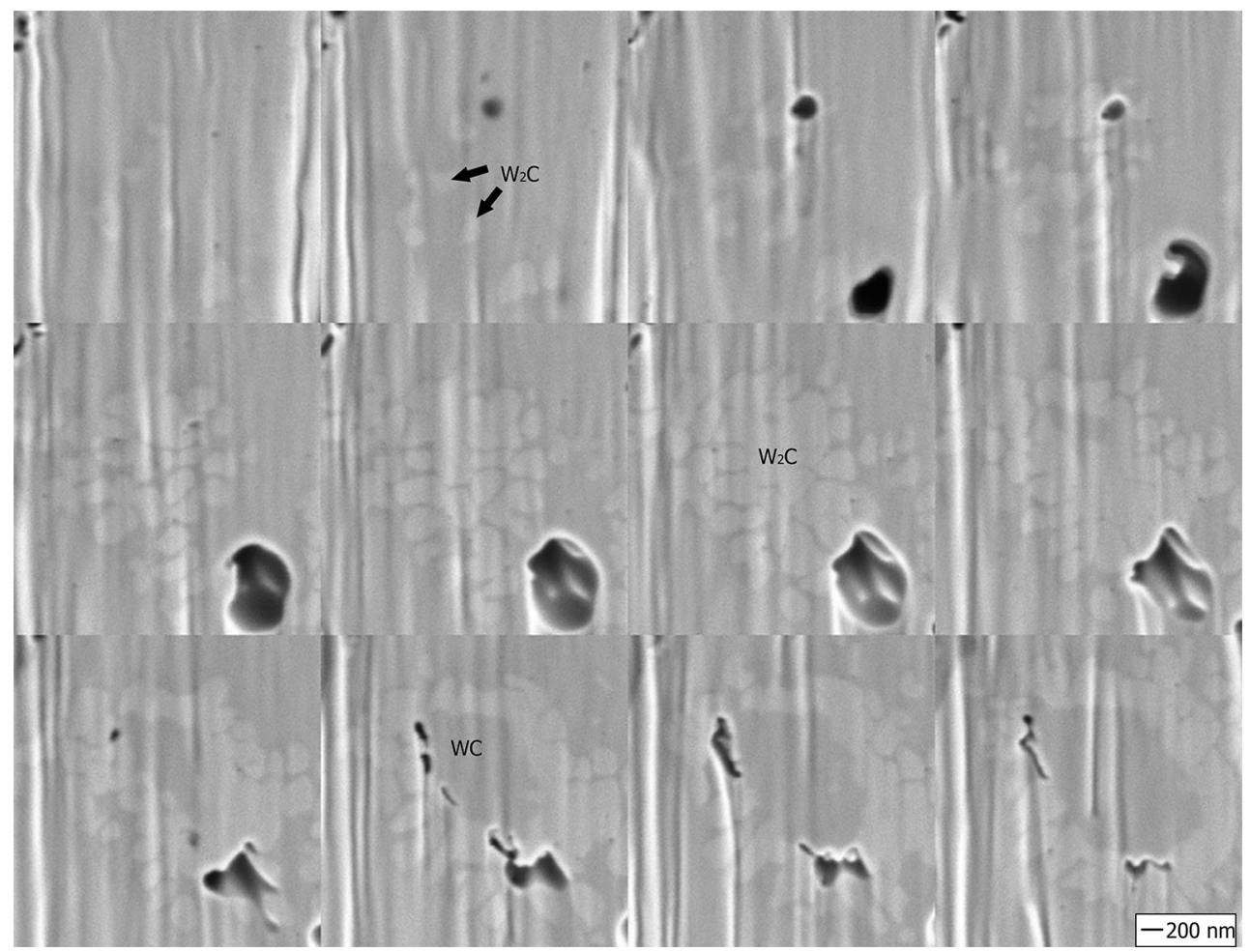

Fig. 11 Montage of twelve images (step size $50 \mathrm{~nm}$ ) featuring the three-dimensional morphology of the $\mathrm{W}_{2} \mathrm{C}$ that has grown on a WC grain

binder during the intense plastic deformation upon impingement of larger particles. The high specific surface area of the examined fine particles is responsible for the required volatile thermal history in-flight which enables the crystallization of metallic W. Porosity in the microstructure has been attributed to gaseous spherical pores and intersplat gaps with distinct morphological features. The semicarbide $\left(\mathrm{W}_{2} \mathrm{C}\right)$ crystals are seen to grow epitaxially on the affected WC grain and extend radially with progressively thinning cross sections.

Acknowledgments The authors gratefully acknowledge support from EPSRC, Grant EP/P001521/1.

Open Access This article is distributed under the terms of the Creative Commons Attribution 4.0 International License (http://crea tivecommons.org/licenses/by/4.0/), which permits unrestricted use, distribution, and reproduction in any medium, provided you give appropriate credit to the original author(s) and the source, provide a link to the Creative Commons license, and indicate if changes were made.

\section{References}

1. J.A. Picas, M. Punset, M. Teresa Baile, E. Martín, and A. Forn, Tribological Evaluation of HVOF Thermal-Spray Coatings as a Hard Chrome Replacement, Surf. Interface Anal., 2011, 43, p 1346-1353

2. L. Berger, Application of Hardmetals as Thermal Spray Coatings, Int. J. Refract. Met. Hard. Mater., 2015, 49, p 350-364
3. V. Katranidis, S. Gu, T.R. Reina, E. Alpay, B. Allcock, and S. Kamnis, Experimental Study of High Velocity Oxy-Fuel Sprayed WC-17Co Coatings Applied on Complex Geometries. Part B: Influence of Kinematic Spray Parameters on Microstructure, Phase Composition and Decarburization of the Coatings, Surf. Coat. Technol., 2017, 328, p 499-512

4. C. Verdon, A. Karimi, and J. Martin, A Study of High Velocity Oxy-Fuel Thermally Sprayed Tungsten Carbide Based Coatings. Part 1: Microstructures, Mater. Sci. Eng. A, 1998, 246, p 11-24

5. J. Yuan, Q. Zhan, J. Huang, S. Ding, and H. Li, Decarburization Mechanisms of WC-Co During Thermal Spraying: Insights From Controlled Carbon Loss and Microstructure Characterization, Mater. Chem. Phys., 2013, 142, p 165-171

6. Q.Zhan, L. Yu, F. Ye, Q. Xue, and H. Li, Quantitative Evaluation of the Decarburization and Microstructure Evolution of WC-Co During Plasma Spraying, Surf. Coat. Technol., 2012, 206, p 4068-4074

7. D.A. Stewart, P.H. Shipway, and D.G. McCartney, Microstructural Evolution in Thermally Sprayed WC-Co Coatings: Comparison Between Nanocomposite and Conventional Starting Powders, Acta Mater., 2000, 48, p 1593-1604

8. S.M. Nahvi and M. Jafari, Microstructural and Mechanical Properties of Advanced HVOF-Sprayed WC-Based Cermet Coatings, Surf. Coat. Technol., 2016, 286, p 95-102

9. S. Usmani, S. Sampath, D.L. Houck, and D. Lee, Effect of Carbide Grain Size on the Sliding and Abrasive Wear Behavior of Thermally Sprayed WC-Co Coatings, Tribol. Trans., 1997, 40, p $470-478$

10. B.H. Kear, G. Skandan, and R.K. Sadangi, Factors Controlling Decarburization in HVOF Sprayed Nano-WC/Co Hard Coatings, Scr. Mater., 2001, 44, p 1703-1707

11. C. Li and G. Yang, Relationships Between Feedstock Structure, Particle Parameter, Coating Deposition, Microstructure and Properties for Thermally Sprayed Conventional and Nanostructured WC-Co, Int J Refract. Met. Hard Mater., 2013, 39, p 2-17 
12. S. Thiele, K. Sempf, K. Jaenicke-Roessler, L. Berger, and J. Spatzier, Thermophysical and Microstructural Studies on Thermally Sprayed Tungsten Carbide-Cobalt Coatings, J. Therm. Spray Technol., 2011, 20, p 358-365

13. C.J. Li, A. Ohmori, and Y. Harada, Formation of an Amorphous Phase in Thermally Sprayed WC-Co, J. Therm. Spray Technol., 1996, 5, p 69-73

14. D.A. Stewart, P.H. Shipway, and D.G. McCartney, Influence of Heat Treatment on the Abrasive Wear Behaviour of HVOF Sprayed WCCo Coatings, Surf. Coat. Technol., 1998, 105, p 13-24

15. V.V. Sobolev and J.M. Guilemany, Dynamic Processes During High Velocity Oxyfuel Spraying, Int. Mater. Rev., 1996, 41, p 1332

16. Technical Bulletin AMPERIT 526 WC-Co 83/17 Agglomerated Sintered, 2011

17. B. Allcock, S. Gu, and S. Kamnis, Nozzle for a Thermal Spray Gun and Method of Thermal Spraying, EP20100711455 (2012)

18. C.A. Schneider, W.S. Rasband, and K.W. Eliceiri, NIH Image to ImageJ: 25 Years of Image Analysis, Nat Methods, 2012, 9, p 671-675

19. V. Katranidis, S. Gu, B. Allcock, and S. Kamnis, Experimental Study of High Velocity Oxy-Fuel Sprayed WC-17Co Coatings Applied on Complex Geometries. Part A: Influence of Kinematic Spray Parameters on Thickness, Porosity, Residual Stresses and Microhardness, Surf. Coat. Technol., 2017, 311, p 206-215

20. V.B. Voitovich, V.V. Sverdel, R.F. Voitovich, and E.I. Golovko, Oxidation of WC-Co, WC-Ni and WC-Co-Ni Hard Metals in the Temperature Range $500-800{ }^{\circ} \mathrm{C}$, Int. J. Refract. Met. Hard Mater., 1996, 14, p 289-295
21. C. Li, A. Ohmori, and Y. Harada, Effect of Powder Structure on the Structure of Thermally Sprayed WC-Co Coatings, J. Mater. Sci., 1996, 31, p 785-794

22. S. Kamnis, S. Gu, and M. Vardavoulias, Numerical Study to Examine the Effect of Porosity on in-Flight Particle Dynamics, $J$. Therm. Spray Technol., 2011, 20, p 630-637

23. A.S. Kurlov and A.I. Gusev, Effect of Particle Size on the Oxidation of WC Powders During Heating, Inorg. Mater., 2011, 47, p $133-138$

24. S. Kamnis and S. Gu, Study of In-Flight and Impact Dynamics of Non-Spherical Particles from HVOF Funs, J. Therm. Spray Technol., 2010, 19, p 31-41

25. Z. Geng, S. Hou, G. Shi, D. Duan, and S. Li, Tribological Behaviour at Various Temperatures of WC-Co Coatings Prepared Using Different Thermal Spraying Techniques, Tribol. Int., 2016, 104, p 36-44

26. G.H. Geiger and D. Poirier, Transport Phenomena in Metallurgy, Addison-Wesley Publishing Company, Boston, 1973, p 616-618

27. C.M. Fernandes and A.M.R. Senos, Cemented Carbide Phase Diagrams: A review, Int. J. Refract. Met. Hard Mater., 2011, 29, p 405-418

28. V.A. Tracey, Nickel in Hardmetals, Int. J. Refract. Met. Hard Mater., 1992, 11, p 137-149

29. D. Fu, H. Xiong, and Q. Wang, Microstructure Evolution and its Effect on the Wear Performance of HVOF-Sprayed Conventional WC-Co Coating, J. Mater. Eng. Perform., 2016, 25, p 4352-4358

30. J.R. Rumble, Handbook of Chemistry and Physics, CRC Press/ Taylor and Francis, 98th edn, Internet Version 2018. Accessed on 12 February 2018. http://hbcponline.com 